\title{
ENRAIZAMENTO DE ESTACAS DE Ginkgo biloba TRATADAS COM ÁCIDO INDOLBUTÍRICO E ACIDO BÓRICO
}

\author{
Rooting of Ginkgo biloba cuttings treated with indolbutyric and boric acids
}

\author{
Janice Valmorbida ${ }^{1}$, Antônio Oliveira Lessa ${ }^{2}$
}

\begin{abstract}
RESUMO
Objetivou-se neste trabalho estudar o efeito do ácido indolbutírico (AIB) e do ácido bórico (B) no enraizamento de estacas de Ginkgo biloba. Em estacas com duas folhas, medindo $15 \mathrm{~cm}$ de comprimento foram provocadas duas lesões na base de aproximadamente

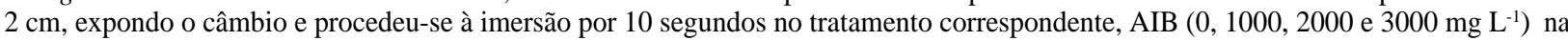
ausência ou presença de B $\left(0\right.$ e $\left.150 \mathrm{mg} \mathrm{L}^{-1}\right)$. Em seguida foram colocadas para enraizar em bandejas de polipropileno contendo areia lavada. O delineamento foi em blocos casualizados num fatorial 4X2, com seis repetições. Foram avaliadas porcentagem de estacas enraizadas, estacas não enraizadas e mortas, diâmetro e comprimento das raízes, aos 70 dias do tratamento. Os dados foram submetidos à análise de variância sendo previamente testados para normalidade pelo Teste de Shapiro-Wilk. As médias foram comparadas pelo Teste de Tukey. Os tratamentos com $2000 \mathrm{mg} \mathrm{L}^{-1}$ de AIB foram superiores à ausência de AIB (80,55\% vs. 55,56\%, respectivamente), não diferindo dos demais tratamentos. A utilização de B não afetou a taxa de enraizamento, de estacas não enraizadas e mortas, não havendo interação entre a concentração de AIB e a utilização ou não de B. O diâmetro e o comprimento das raízes não foram afetados pela utilização de AIB e B.
\end{abstract}

Termos para indexação: Auxinas, Ginkgo biloba, propagação vegetativa.

\section{ABSTRACT}

The aim of the work was to study the effect of indolbutyric (IBA) and boric (B) acids to root Ginkgo biloba cuttings. At the base of cuttings, with two leaves and $15 \mathrm{~cm}$ of length, were made two lesions with $2 \mathrm{~cm}$ to expose the cambium. Cuttings were treated for a period of 10 seconds with four concentrations of IBA $\left(0,1000,2000\right.$ and $\left.3000 \mathrm{mg} \mathrm{L}^{-1}\right)$ combined with two concentration of B $\left(0\right.$ and $\left.150 \mathrm{mg} \mathrm{L}^{-1}\right)$. After that, cuttings were taken in polypropylene trays filled with washed sand. The experimental design was of randomized blocks in the factorial arrangement (4x2), with six replications. After 70 days, evaluations were done considering rooted, non-rooted, and dead cuttings, diameter and length of the roots. The data were submitted to ANOVA and previously tested for normality by the Shapiro-Wilk Test. Rooting with IBA at $2000 \mathrm{mg} \mathrm{L}^{-1}(80,55 \%)$ was better than IBA at zero $\mathrm{mg} \mathrm{L}^{-1}(55,56 \%)$, not differing from the other treatments. Boric acid (B) at $150 \mu \mathrm{g} \mathrm{mL}^{-1}$ didn't increase rooting rate, and dead cuttings. There was no interaction between IBA and B concentrations. No effect of IBA or B in the diameter and the length of roots was observed.

Index terms: Auxin, Ginkgo biloba, vegetative propagation.

\section{(Recebido em 18 de maio de 2006 e aprovado em 1 de março de 2007)}

\section{INTRODUÇÃO}

A Ginkgo biloba L. é uma espécie nativa da China e, provavelmente, do Japão e da Coréia. É considerada um fóssil vivo, tendo surgido há quase 200 milhões de anos (MAJOR, 1967). Planta arbórea, perene, pode atingir um porte de 30 a 40 metros, mas normalmente fica em torno de $15 \mathrm{~m}$ de altura. É uma planta dióica, apresenta folhas em forma de leque, normalmente bilobadas, com nervuras radiantes (REITZ, 1984). Segundo Major (1967) e Michel (1986) a longevidade da árvore e a sua sobrevivência ao longo de centenas de milhões de anos podem ser explicadas pela sua alta resistência a pragas, doenças (fungos e viroses) e à poluição. No Brasil, não se tem relatos de frutificação e produção de sementes da espécie.

A G. biloba é bem conhecido como um remédio natural e os registros de seu uso datam de 2800 a.C. (BALCH, 2000). Como propriedades terapêuticas citamse: ativadora das funções circulatórias, anti-radicais livres (ALLARD, 1986), diurética (ALONSO, 1998), preventiva de edema cerebral e preventivo profilático do envelhecimento celular (TESKE \& TRENTINI, 1997), entre outras. O extrato de ginkgo é prescrito em distúrbios psíquicos e do comportamento de idosos, em deficiências vasculares periféricas, demência, hipoxia, mal de Alzheimer e em distúrbios funcionais de origem isquêmica (ALLARD,

\footnotetext{
'Engenheira Agrônoma, Doutora em Agronomia/Horticultura - Departamento de Produção Vegetal - Faculdade de Ciências Agronômicas/FCA Universidade Estadual Paulista/ UNESP - Fazenda Lageado - Cx. P. 237-18603-970 - Botucatu, SP - jvalmorbida@yahoo.com.br-Bolsista CAPES. ${ }^{2}$ Engenheiro Agrônomo, Doutor em Fitotecnia/Horticultura - Laboratório de Biotecnologia - Estação Experimental de Lages/EEL - Empresa Pesquisa Agropecuária e Extensão Rural de Santa Catarina - EPAGRI - Rua Joaõ José Godinho, s/n - Morro do Posto - Cx. P. $88502-970$ - Lages, SC aolessa@epagri.rct-sc.br
} 
1986; FONG \& KINNER, 2003). As partes utilizadas na fitoterapia são as folhas e as sementes, essas indicadas para aliviar a respiração ofegante, diminuir o catarro e tratar corrimentos vaginais, incontinência e vesícula debilitada (CHEVALLIER, 1996).

O principal hormônio vegetal responsável pelo enraizamento é a auxina, oriunda de regiões meristemáticas da planta (HARTMANN et al., 2002). Para os autores, o ácido indolbutírico (AIB) e o ácido naftaleno-acético (ANA) são as auxinas mais utilizadas no tratamento das estacas.

Segundo Shelp (1993) e Taiz \& Zeiger (2004), evidências sugerem que o boro desempenha funções no alongamento celular, síntese de ácidos nucléicos, respostas hormonais e funcionamento de membranas. É conveniente considerar a iniciação e o crescimento de raízes processos distintos, nos quais a auxina é o iniciador das raízes, mantendo o boro (B) o crescimento das mesmas (HEMBERG, 1951; MIDDLETON et al., 1978). Ono et al. (1993) enraizaram estacas de hortênsia e verificaram que o boro sozinho tem pequena influência sobre o enraizamento, porém quando misturado a uma auxina aumenta a formação de raízes. $\mathrm{O}$ boro adicionado à auxina se faz necessário para que ocorra um melhor desenvolvimento das raízes (ONO et al., 1992).

Jarvis et al. (1983), em estacas de Phaseolus aureus Roxb., relatam que o boro, direta ou indiretamente, aumenta a oxidação do IAA (ácido indolacético) endógeno, diminuindo assim, os níveis de auxinas até uma concentração efetiva, controlando, dessa forma as concentrações eficientes desse hormônio para o crescimento das raízes.

Objetivou-se nesse trabalho estudar o efeito do ácido 3-indolbutírico (AIB) e do ácido bórico (B) no enraizamento de estacas de Ginkgo biloba, com isso contribuindo para diminuir a escassez de trabalhos de multiplicação por estacas dessa espécie, disponibilizando um protocolo de enraizamento.

\section{MATERIALE MÉTODOS}

Estacas de Ginkgo biloba provenientes de uma única matriz foram coletadas no mês de dezembro de 2004 , sendo preparadas no setor de aclimatação da Estação Experimental da Empresa de Pesquisa Agropecuária e Extensão Rural de Santa Catarina (EPAGRI), Lages (SC). Apresentando clima subtropical e localizada a uma altitude de $904 \mathrm{~m}$ acima do mar, com uma temperatura média anual de $16^{\circ} \mathrm{C}$, a região de Lages (SC) favorece a adaptação da espécie Ginkgo biloba.

Em estacas lenhosas, com duas folhas, duas a três gemas, medindo $15 \mathrm{~cm}$ de comprimento e, em média, $6 \mathrm{~mm}$ de diâmetro foram provocadas duas lesões na base, de aproximadamente $2 \mathrm{~cm}$, expondo o câmbio. Em seguida, as bases das estacas foram mergulhadas, por 10 segundos, em soluções aquosas contendo ácido 3-indolbutírico (AIB), diluído com hidróxido de sódio, misturadas ou não com ácido bórico $\left(\mathrm{H}_{3} \mathrm{BO}_{3}\right)$ a $150 \mathrm{mg} \mathrm{L}^{-1}$.

O delineamento experimental foi em blocos casualizados num fatorial $4 \mathrm{X} 2$, sendo 4 concentrações de AIB $\left(0,1000,2000\right.$ e $\left.3000 \mathrm{mg} \mathrm{L}^{-1}\right)$ na ausência ou presença de boro ( 0 e $\left.150 \mathrm{mg} \mathrm{L}^{-1}\right), 6$ estacas por tratamento, 6 blocos, totalizando 288 estacas. Após a aplicação dos tratamentos, as estacas foram plantadas em bandejas de poliestireno expandido de 72 células, contendo areia lavada. Foram mantidas em túnel de aclimatização, sem controle de temperatura, com nebulização intermitente de 1 minuto a cada hora. Esse sistema garantiu uma temperatura máxima de $25 \pm 5^{\circ} \mathrm{C}$ e uma umidade relativa maior do que $70 \%$. O experimento foi avaliado aos 70 dias após a implantação, sendo analisados os seguintes dados biométricos: porcentagem de estacas enraizadas (estacas vivas e com indução de primórdios radiciais de no mínimo $0,5 \mathrm{~cm}$ de comprimento, com a ocorrência ou não de calos), porcentagem de estacas não enraizadas e mortas, comprimento e diâmetro (média) das raízes formadas.

Os dados foram submetidos à análise de variância, sendo previamente testados para normalidade pelo Teste de Shapiro-Wilk. As médias foram comparadas pelo Teste de Tukey, ao nível de 5\% de probabilidade.

\section{RESULTADOS E DISCUSSÃO}

A utilização do ácido 3-indolbutírico (AIB) afetou a taxa de enraizamento de estacas de Gingko biloba. A aplicação da concentração de $2000 \mathrm{mg} \mathrm{L}^{-1}$ promoveu maior taxa de enraizamento em relação à ausência de AIB. As demais concentrações de AIB apresentaram valores intermediários (Tabela 1), todos maiores do que $50 \%$. Leonel \& Rodrigues (1995) trabalharam com várias concentrações de AIB no enraizamento de lichia (Litchi chinensis Sonn.), obtendo 83,33\% de enraizamento com $5000 \mathrm{mg} \mathrm{L}^{-1}$ da auxina. No presente trabalho, houve a formação de raízes em todos os tratamentos, intensificados com o uso de AIB, demonstrando ser a espécie G. Biloba de fácil propagação. Contudo, algumas espécies, como a goiabeira serrana (Feijoa sellowiana) são difíceis de enraizar, mesmo com o uso de altas concentrações de AIB, iguais a 5000, 7000, 9000 e $11000 \mathrm{mg} \mathrm{L}^{-1}$ (FIGUEIREDO et al., 1995). É importante testar várias concentrações do regulador vegetal, permitindo a escolha mais econômica e menos fitotóxica para a espécie. Oliveira et al. (2003) 
Tabela 1 - Efeito dos níveis do ácido indolbutírico (AIB) sobre a porcentagem de estacas enraizadas, não enraizadas e mortas da espécie Ginkgo biloba, avaliadas 70 dias após o tratamento.

\begin{tabular}{cccc}
\hline & \multicolumn{3}{c}{ Estacas } \\
\cline { 2 - 4 }$\left(\begin{array}{c}\text { AIB } \\
\left(\mathrm{m} \mathrm{L} \mathrm{L}^{-1}\right)\end{array}\right.$ & $\begin{array}{c}\text { Enraizadas } \\
(\%)\end{array}$ & $\begin{array}{c}\text { Não Enraizadas } \\
(\%)\end{array}$ & $\begin{array}{c}\text { Mortas } \\
(\%)\end{array}$ \\
\hline 0 & $55,56 \mathrm{~b}$ & $27,78 \mathrm{a}$ & $16,67 \mathrm{a}$ \\
1000 & $72,22 \mathrm{ab}$ & $15,28 \mathrm{ab}$ & $12,50 \mathrm{a}$ \\
2000 & $80,55 \mathrm{a}$ & $11,11 \mathrm{~b}$ & $8,33 \mathrm{a}$ \\
3000 & $72,22 \mathrm{ab}$ & $8,33 \mathrm{~b}$ & $19,44 \mathrm{a}$ \\
\hline
\end{tabular}

Médias seguidas de mesma letra não diferem entre si ao nível de $5 \%$ de probabilidade.

recomendam, após testar o enraizamento de oliveira (Olea europaea L.), com diferentes concentrações de AIB, a utilização de $3000 \mathrm{mg} \mathrm{L}^{-1}$, que resultou em 44,28\% de enraizamento. No enraizamento de estacas de pessegueiro, Mindêllo Neto (2005) obteve $100 \%$ de enraizamento quando utilizou $2000 \mathrm{mg} \mathrm{L}^{-1}$ de AIB junto com a aplicação de um fertilizante orgânico.

A utilização de B não afetou a taxa de enraizamento e de sobrevivência das estacas, não sendo observada interação entre a concentração de AIB e a utilização ou não de boro. As taxas médias de enraizamento foram de 71,53 e $68,75 \%$ para os níveis de zero e $150 \mathrm{mg} \mathrm{L}^{-1}$, respectivamente. Ono et al. (1995) testaram o efeito de auxinas e boro no enraizamento de estacas de kiwi e não observaram efeito positivo da adição do boro às soluções auxínicas, não havendo incremento na porcentagem de enraizamento.

A menor taxa de enraizamento, em estacas que não receberam AIB, está vinculada a um maior porcentual de estacas não enraizadas, não havendo efeito das taxas de estacas mortas (Tabela 1). Observações visuais constataram a ocorrência de calos na base das estacas, tanto as enraizadas quanto as não enraizadas. Leonel \& Rodrigues (1993) estudaram as interações entre as auxinas AIB e ANA e boro em estacas de lichieira e constataram que a persistência das folhas nas estacas possibilitou uma maior sobrevivência dessas, estimulando a formação dos calos. Os mesmos autores obtiveram uma maior sobrevivência de estacas de lichieira, quando combinaram AIB mais Boro nos tratamentos. No presente trabalho, mesmo as estacas que não enraizaram mantiveram suas folhas verdes.

Estacas com raízes bem formadas permitem o desenvolvimento de uma muda de melhor aclimatização e desenvolvimento. No presente trabalho, o comprimento e o diâmetro médio das raízes foram $1,78 \mathrm{~cm}$ e 1,56 mm, respectivamente, não tendo sido afetados pela utilização de AIB e B. Visualmente, as raízes de G. biloba, apresentavam uniformidade e sanidade. Quando Tofanelli et al. (2002) enraizaram cultivares de ameixeira com AIB, obtiveram, na avaliação aos 60 dias dependendo das cultivares, comprimentos de raízes entre $0,13 \mathrm{~cm}$ (estacas lenhosas) até $4,75 \mathrm{~cm}$ (estacas semilenhosas), onde 3000 $\mathrm{mg} \mathrm{L}^{-1}$ de AIB permitiu maior porcentagem de estacas enraizadas. Algumas espécies, como a aceroleira (Malpighia glabra), tratadas com $2800 \mathrm{mg} \mathrm{L}^{-1}$ de AIB, apresentaram $50 \%$ de enraizamento e raízes com comprimento médio de $9 \mathrm{~cm}$, na avaliação aos 100 dias (GONTIJO et al., 2003).

\section{CONCLUSÕES}

A exposição de estacas de Ginkgo biloba por 10 segundos ao AIB, na concentração de $2000 \mathrm{mg} \mathrm{L}^{-1}$, promoveu uma maior porcentagem de enraizamento nas condições desse experimento.

O boro não mostrou efeito no enraizamento de Ginkgo biloba.

\section{AGRADECIMENTOS}

À Professora Claudete Nuernberg, pela disponibilização do material vegetativo.

À Estação Experimental da Epagri Lages, por permitir a realização do trabalho e por disponibilizar o material necessário.

\section{REFERÊNCIA BIBLIOGRÁFICA}

ALLARD, M. Treatment of the disorders of aging with Ginkgo biloba extract: from pharmacology to clinical medicine. Presse Medicale, [S.1.], v. 15, n. 31, p. 1540-1545, 1986.

ALONSO, J. R. Tratado de fitomedicina: bases clínicas y farmacológicas. Buenos Aires: Isis Ediciones S.R.L., 1998. $1039 \mathrm{p}$. 
BALCH, J. F. 10 remédios naturais que podem salvar sua vida. Rio de Janeiro: Campus, 2000. 237 p.

CHEVALLIER, A. The encyclopedia of medicinal plants. Londres: DK, 1996. 336 p.

FIGUEIREDO, S. L. B.; KERSTEN, E.; SCHUCH, M. W. Efeito do estiolamento parcial e do ácido indolbutírico (IBA) no enraizamento de estacas de ramos de goiabeira serrana (Feijoa sellowiana, Berg). Science Agricola, Piracicaba, v. 52, n. 1, p. 167-171, 1995.

FONG, K. C. S.; KINNER, P. E. Retrobulbar haemorrhage associated with chronic Ginkgo biloba ingestion. Postgraduate Medical Journal, [S.1.], v. 79, p. 531-532, 2003.

GONTIJO, T. C. A.; RAMOS, J. D.; MENDONÇA, V.; PIO, R.; ARAÚJO NETO, S. E. de; CORRÊA, F. L. de O. Enraizamento de diferentes tipos de estacas de aceroleira utilizando ácido indolbutírico. Revista Brasileira de Fruticultura, Jaboticabal, v. 25, n. 2, p. 290-292, 2003.

HARTMANN, H. T.; KESTER, D. E.; DAVIS JUNIOR, F. T.; GENEVE, R. L. Plant Propagation: principles and practices. 7. ed. New York: Englewood Clipps, 2002. 880 p.

HEMBERG, T. Rooting experiments with hypocotyls of Phaseolus vulgaris L. Physiology Plant, Copenhagen, v. 4, p. 358-369, 1951.

JARVIS, B. C.; ALI, A. H. N.; SHAMEED, A. I. Auxin and boron in relation to the response and ageing of mung bean cuttings. New Phytology, Cambridge, v. 92, p. 509-518, 1983.

LEONEL, S.; RODRIGUES, J. D. Enraizamento de estacas de lichia (Litchi chinensis SONN.). Science Agricola, Piracicaba, v. 52, n. 2, p. 335-338, 1995.

LEONEL, S.; RODRIGUES, J. D. Efeitos da aplicação de reguladores vegetais e do ácido bórico em estacas de lichieira (Litchi chinensis SONN.). Science Agricola, Piracicaba, v. 50, n. 1, p. 33-39, 1993.

MAJOR, R. T. The ginkgo, the most ancient living tree: the resistance of Ginkgo biloba L. to pests accounts in part for the longevity of this species. Science, [S.1.], v. 157, n. 794, p. 1270-1273, 1967.

MICHEL, P. F. The doyen of trees: the Ginkgo biloba. Presse Medicale, [S.1.], v. 15, n. 31, p. 1450-1454, 1986.
MIDDLETON, W.; JARVIS, B. C.; BOOTH, A. The boron requirement for roots development in stem cutting of Phaseolus aureus Roxb. New Phytology, Cambridge, v. 81, p. $287,1978$.

MINDÊLLO NETO, U. R. Enraizamento de estacas de pessegueiro em função do uso de ácido indolbutírico e fertilizante orgânico. Revista Brasileira de Fruticultura, Jaboticabal, v. 27, n. 1, p. 92-94, 2005.

OLIVEIRA, A. F. de; PASQUAL, M.; CHALFUN, N. N. J.; REGINA, M. de A.; RINCÓN, C. D. R. Enraizamento de estacas semilenhosas de oliveira sob efeito de diferentes épocas, substratos e concentrações de ácido indolbutírico. Ciência e Agrotecnologia, Lavras, v. 27, n. 1, p. 117-125, 2003.

ONO, E. O.; RODRIGUES, J. D.; PINHO, S. Z. de. Efeitos de auxinas e boro sobre o enraizamento de estacas caulinares de kiwi (Actinidia chinensis Pl. cv Matua). Phyton, Argentina, v. 57, n. 2, p. 137-147, 1995.

ONO, E. O.; RODRIGUES, S. D.; RODRIGUES, J. D. Efeito de misturas de ácido indol-butírico e ácido naftalenoacético mais boro, sobre o enraizamento de estacas de hortênsia (Hydrangea macrophylla SER.). Naturalia, São Paulo, v. 18, p. 83-93, 1993.

ONO, E. O.; RODRIGUES, S. D.; RODRIGUES, J. D. Interações entre auxinas e boro no enraizamento de estacas de camélia. Revista Brasileira de Fisiologia Vegetal, Campinas, v. 4, n. 2, p. 107-112, 1992.

REITZ, R. Ginkgoáceas. Itajaí: Herbário Barbosa Rodrigues, 1984. 7 p. (Flora Ilustrada Catarinense).

SHELP, B. J. Physiology and biochemistry of boron in plants. In: Boron and its role in crop production. Boca Raton: CRC, 1993. p. 53-85.

TAIZ, L.; ZEIGER, E. Fisiologia vegetal. 3. ed. Porto Alegre: Artmed, 2004. 719 p.

TESKE, M.; TRENTINI, A. M. M. Compêndio de fitoterapia. 3. ed. Curitiba: Herbarium, 1997. 317 p.

TOFANELLI, M. B. D.; CHALFUN, N. N. J.; HOFFMANN, A.; CHALFUN JÚNIOR, A. Enraizamento de estacas lenhosas e semilenhosas de cultivares de ameixeira com várias concentrações de ácido indolbutírico. Revista Brasileira de Fruticultura, Jaboticabal, v. 24, n. 2, p. 509-513, 2002. 